\title{
LA TEORÍA DE LAS INTELIGENCIAS MÚLTIPLES DE GARDNER APLICADAS AL CAMPO DE LA JUSTICIA
}

GARDNER'S MULTIPLE INTELLIGENCE THEORY APPLIED TO THE FIELD OF JUSTICE

\section{Wael Sarwat Hikal Carreón}

Sociedad Mexicana de Criminología capítulo Nuevo León A.C., México

Correspondencia:wael.hikalcrr@uanl.edu.mx

\section{RESUMEN}

La intervención de profesionales en asuntos de materia criminal implica el desarrollo de habilidades de investigación sobre diversos hechos que se presentan en su quéhacer profesional, ya sea trabajando con personas víctimas, criminales, testigos, sospechosos, o instrumentos en la investigación pericial. La teoría de las inteligencias múltiples de Howard Gardner plantea 8 tipos de habilidades en las que los seres humanos pueden tener desarrollado más alguna que otra, las concibe como un conjunto de capacidades y desarrollo de conocimientos que se aplican en áreas de la vida. En diversos ámbitos profesionales de la investigación criminal, que abarca a psicólogos, médicos, jueces, juristas, criminólogos, criminalistas, entre otros, se requieren de esas capacidades para investigar adecuadamente el hecho al que se tiene enfrente. Este artículo muestra una articulación de cada una de las ocho inteligencias aplicadas al ámbito de investigación criminal.

Palabras clave: Cognición, crimen, justicia, inteligencia.

\section{ABSTRACT}

The intervention of professionals in criminal issues involves the development of investigative skills on various facts that arise in their professional work, whether working with victims, 
criminals, witnesses, suspects, or instruments in expert research. Howard Gardner's multiintelligence theory poses 8 types of skills in which humans can have developed more than another, conceived them as a set of skills and knowledge development that are applied in areas of life. In various professional fields of criminal investigation, which encompasses psychologists, physicians, judges, jurists, criminologists, criminalists, among others, these capacities are required to properly investigate facts. This article shows an articulation of each of the eight intelligences applied to the field of criminal investigation.

Key words: Cognition, crime, justice, intelligence.

\section{INTRODUCCIÓN}

La teoría de las inteligencias múltiples de Gardner, detalla diversos niveles de inteligencias o capacidades, no como algo unitario, sino fragmentadas las habilidades de los seres humanos para aplicar los conocimientos a determinado problema o producción de utilidad. El mismo Gardner define la inteligencia como: "capacidad de resolver problemas o de crear productos que sean valiosos en uno o más ambientes culturales", asimismo "la capacidad biopsicológica de procesar información para resolver problemas o crear productos que son valiosos para una comunidad o cultura" (como se citó en Suárez, Maíz y Meza, 2010, p. 84).

Antes de la legitimización de la teoría de Gardner, se tenía la idea que la inteligencia era una unitaria e integral forma de intervención o ajuste de ideas dirigidos a unas situaciones específicas o variadas. Pero Gardner propone la multiplicidad de inteligencias de las cuales, los individuos tienen mayor desarrollo en algunas, pero que también se unen estas para focalizarlas a una hecho, el desarrollo de una $\mathrm{u}$ otra, puede ser en mayor o menor medida según la persona desde su enfoque genético o formación social, escolar o laboral (Luca, 2004). 


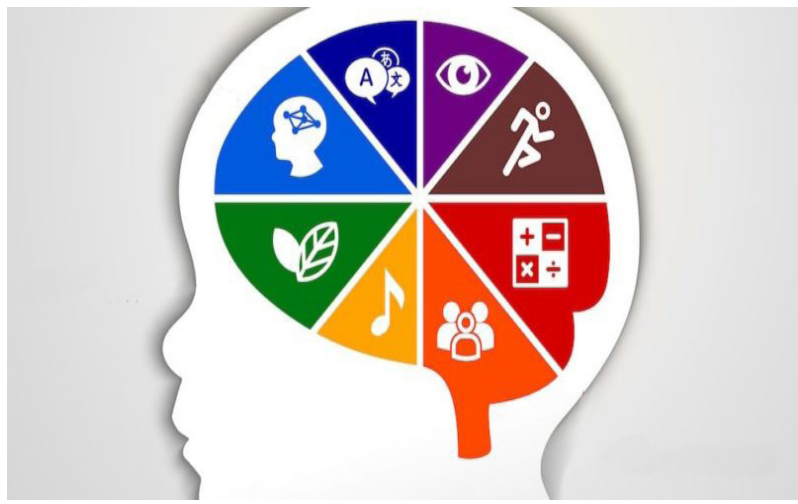

Figura 1. Teoría de las inteligencias múltiples.

Recuperado de https://concepto.de/teoria-de-las-inteligencias-multiples/

En el ámbito de la investigación criminal, victimal, forense, y otros relacionados uno con otro o individualizados, los profesionales requieren de múltiples habilidades de instrumentación oral, verbal, herramientas, percepción, expresión, entre otras que se engloban en las 8 inteligencias propuestas por Gardner (Macías, 2002).

Lo anterior se enfoca a los casos de atención a víctimas de probables delitos, donde según el delito es el modo de atender o abordar a los sujetos, por otro lado, si se trata del médico o criminalista en múltiples ambientes donde se ha dado cierto hecho que se presume delictuoso, ha de aplicar ciertas habilidades que varían de contexto en contexto, por el lado de jueces, abogados, defensores, acusadores, la interpretación es factor importante, así, no siendo limitativa la lista anterior, sino descriptiva brevemente por las profesionales más ocupados en este ambiente, se mencionan, mismas que serán reiteradas en la explicación de las inteligencias para su ámbito profesional.

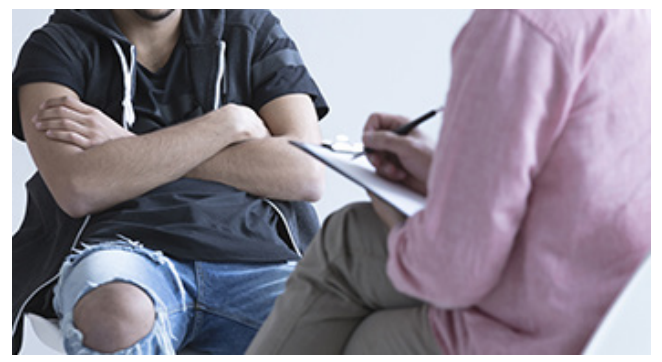

Figura 2. Psicología penitenciaria.

Recuperado de https://www.portaleducacao.com.br/curso-online-psicologia-psicologia-penitenciaria/p 


\section{LAS INTELIGENCIAS MÚLTIPLES}

Cualquiera que sea el problema que hay que atender, implica una meta, que debe atravesar por varias modalidades para su atención, previo a un proceso de sistematización de ideas, que de un abanico de opciones, se pretende elegir la que mejor proporcione vías de solución al caso específico, ya sea que tal proceso comience en sí mismo o con la colaboración de otros aconsejadores por sus vivencias o experiencias, en ocasiones las situaciones nos resultan difíciles por la naturaleza del suceso o por la falta de capacidad para articular las ideas y enfocarlas al hecho (Macías, 2002).

La creación de productos culturales con valor social implican canalizar las inteligencias en algo que sea de utilidad para un problema, servicio, atención, mejora, etcétera; por ejemplo, de una gripa en un niño, el médico organizará los conocimientos adquiridos en su formación, agregado a sus experiencias, para generar una estrategia para atender ese caso particular. A cada caso, corresponden estrategias, ya sea para atender reclamos sociales, violencia, falta de alumbrado, de seguridad, falta de luz, agua, entre otros bienes o servicios (DortaArmaignac, 2010). Los tipos de inteligencias que Gardner propuso son ocho (Velásquez de Romero, 2016; Macías, 2002):

I Inteligencia lingüística: Este tipo de inteligencia se viene trabajando en los seres humanos desde el nacimiento, se nos enseña con la práctica a decir palabras, expresarlas, relacionarlas con un sentimiento, aprenderlas y saber comunicarlas. Durante toda la vida, buscamos formas de expresión oral, escrita mediante actos, palabras, escritos, entre otros, que deben por separado o en conjunto demostrar nuestro pensamiento.

I Inteligencia musical: Comprendida por la capacidad para descifrar notas, instrumentos, canciones, percibir sentimientos, o internalizar en la música el sentir individual, colectivo, de un momento, pero primordialmente, consiste en la capacidad para tomar un instrumento y saberlo desempeñar.

I Inteligencia lógico-matemática: Esta por mucho tiempo ha sido la reina de las inteligencias, donde los exámenes de evaluación se basan en grandes apartados a la solución de problemas matemáticos. Saber comprender, interpretar números, su significado, conceptos. 
IInteligencia cenestésico-corporal: Se utiliza para expresar sentimientos a través de movimientos corporales; por ejemplo, los actores o bailarines, tienen desarrollado este tipo de inteligencia.

I Inteligencia espacial: Es la capacidad de construir, reconstruir e interpretar figuras, imágenes, manipularlas en nuestra mente, detectarlas, descubrir.

IInteligencia intrapersonal: Útil para construirse a sí mismo, saber elegir, tomar decisiones, autoconocerse, reflexionar sobre el autosentir y encaminar decisiones en base a este conocimiento propio

I Inteligencia interpersonal: Consiste en percibir, prestar atención a las cosas de los demás, pueden ser sus sentimientos, gustos, quejas, motivaciones, intereses, sus expresiones o el significado de estas.

I Inteligencia naturalística: Permite discriminar objetos de la naturaleza, identificarlos, diferenciarlos, fenómenos de la naturaleza, permite la evolución, adaptación, tener un conocimiento del ambiente que nos rodea, natural, animal, vegetal, espacial.

\section{LAS INTELIGENCIAS APLICADAS EN LA INTERVENCIÓN EN PROBLEMAS DE JUSTICIA}

Se enfocaran las inteligencias a contextos de atención a víctimas de delitos; por ejemplo, niños, niñas, adolescentes, mujeres adultas, testigos, etcétera, ligado mucho a la intervención del psicólogo forense. Por otro lado, al médico y criminalista, cuya labor en presuntos hechos delictivos en el campo o en gabinete, su habilidad debe focalizarse a los elementos que rodean el hecho, vincularlos, entrelazar; en el caso de jueces o abogados, interpretar lo que los anteriores profesionales han dictaminado y estudiado, entre otras funciones. Al criminólogo al sostener la articulación de políticas para generar estrategias preventivas, diagnósticos participativos, la labor de diagnóstico penitenciario.

Comenzando en el mismo orden listado de las inteligencias y ejemplificando con situaciones de hechos de violencia que se pueden consultar en medios de comunicación, para que el lector tenga su propia apreciación sin limitarlo a un contexto específico donde posiblemente no tenga acceso al caso, por el contrario, se proporcionará el título del caso como los mismos medios de comunicación lo han expresado, para que le facilite su búsqueda, en las cuales el profesional actuará: 
Inteligencia lingüística: Los profesionales de la psicología forense y criminólogos, se han de encontrar ante casos de violaciones sexuales, abusos, maltrato, ofensas (Novo, Herbón y Amado, 2016), lesiones, las anteriores pueden ser de una sola ocasión por algún sujeto conocido o desconocido, o de forma reiterada a largo plazo, víctimas que han sido dañadas en su físico, emociones, mente, que les torna reprimidos, temerosos, desconfiados, inseguros, o agresivos. Por ejemplo, existen niños que crecen en ambientes desfavorables para su sano desarrollo, lo que ocasiona efectos en su crecimiento personal (Mata, Gómez-Pérez y Calero, 2017).

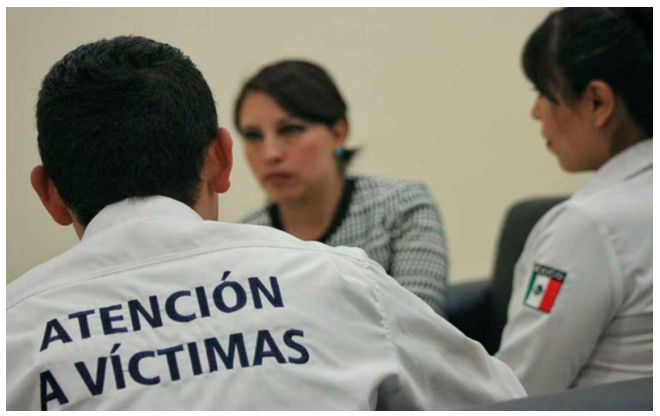

Figura 3. CEEAC fortalece esquemas de atención a la ciudadanía. Recuperado de https://www.elsoldesanluis. com.mx/local/ceeav-fortalece-esquemas-de-atencion-a-la-ciudadania-3952667.html

El profesional debe tener la capacidad para saber expresar lo que le ha ocurrido a la víctima, sin que le reitere el sufrimiento que ya le ha ocurrido, tener un manejo suave y adecuado de las palabras, para que resulta comprensivo el hecho a los sujetos victimizados, no manejar el lenguaje de: "Fuiste violada por tus padres", sino diluir las palabras para que no resulte aún más traumático. Durante el tratamiento, el profesional deberá elegir las técnicas y oratoria adecuada para logar la confianza de la víctima, poder obtener del mejor modo información sobre las situaciones que padeció la persona, de ahí mismo, podrá enarbolar la estrategia terapéutica.

A continuación se muestran una nota periodística titulada: "PGJ busca a taxista que presuntamente viola a pasajeras cerca de AICM", PGJ son las siglas de Procuraduría General de Justicia, y AICM, Aeropuerto Internacional de la Ciudad de México, ambas en la capital del país; es decir, Ciudad de México. Liga https://www.milenio.com/policia/aicm-operataxista-presuntamente-viola-pasajeras. En México, en la capital y otras regiones, vienen ocurriendo hecho lamentables contra mujeres principalmente, menores que al solicitar servicios de transporte privado por aplicaciones digitales o en sitios específicos para ello o en 
calle, ocurre les drogan con fines de robo o violación, han ocurrido casos donde abandonan los cuerpos en montes, aún con vida o privadas de esta.

La inteligencia lingüística aquí debe operar además para comunicar lo menos golpeante posible a los familiares víctimas, en ocasiones los medios de comunicación impresos, televisivos, digitales, u otros, arrojan las notas de modo directo e incluso exagerado, en una estrategia de comunicación que provoca al morbo, y se aleja del respeto a las víctimas, que además difunde el hecho, generando una sensación de inseguridad.

También está el caso de los operadores telefónicos, muy visto en programas de televisión que emiten documentales reales, el tipo de empatía que expresan algunos operadores telefónicos para transmitir y generar tranquilidad, así como procurar la obtención de más datos de utilidad para el estudio del caso. Este aspecto positivo por un lado, mientras que por otro, están los malos tratos, negatividad, indiferencia, por ejemplo, véase la siguiente nota titulada "En Estados Unidos una operadora del 911 cortó miles de llamadas de emergencia" en https:/www.eluniverso.com/noticias/2016/10/13/ nota/5852056/estados-unidos-operadora-911-corto-miles-1lamadas-emergencia. La habilidad para comunicar y expresar información a víctimas directas y colaterales, guarda estrecha relación en este tipo de inteligencia y el modo adecuado.

Inteligencia musical: Aquí interviene una variedad de inteligencias, para percibir e interpretar hechos, por ejemplo de suicidios, influencias, manipulaciones, y actos donde los actores del hecho criminal, usan como banda sonora de su propio acto, determinada música, siendo innegable el uso e influencia de esta, sobre los sentimientos, estado de ánimo y actuar en las personas.

La siguiente nota titulada: "Satanismo, quema de iglesias y asesinatos: la verdadera historia de 'Lords of Chaos", publicada por Los Angeles Times, https://www.latimes.com/espanol/ entretenimiento/la-en-satanismo-quema-de-iglesias-y-asesinatos-la-verdadera-historia-delords-of-chaos-20190212-story.html, se refiere a un grupo noruego que formaron una banda de música, con gustos por el metal pesado, películas sangrientas, la rebeldía y maldad, que posteriormente, un miembro de la banda asesina a otro, y uno de ellos se suicida. Apunta el periodista Appleford (2019): "Fue un promotor descarado de la banda y exagerador de la mala intención". En una entrevista a un integrante de la banda, expresó: "No queremos a ninguna... groupie. Lo nuestro es la destrucción y el sufrimiento. Cuando la gente escucha nuestra música, queremos que se suiciden" (Appleford, 2019). 


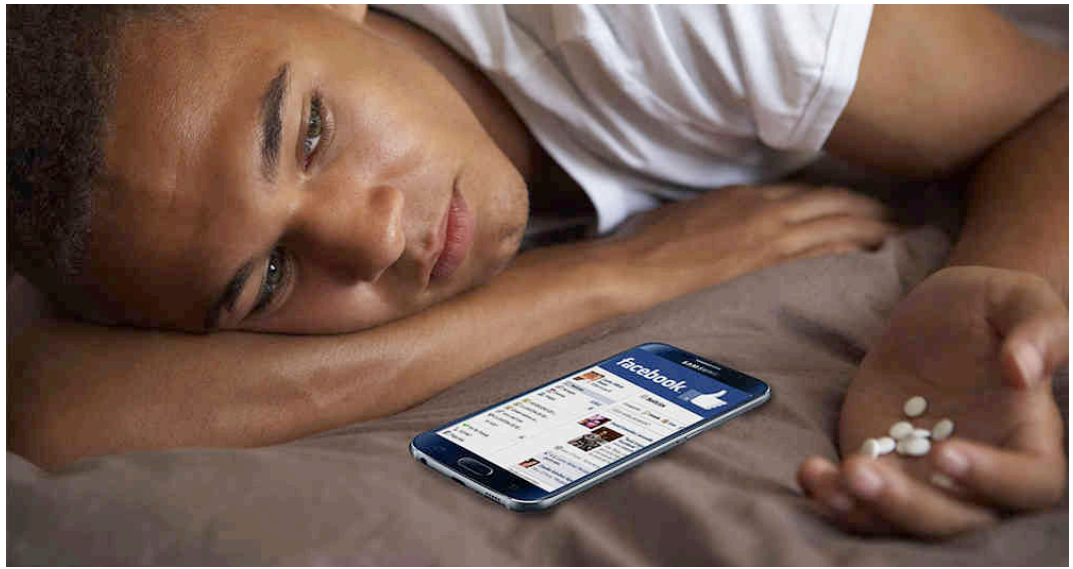

Figura 4. ¿Aumento de suicidios tiene que ver con el uso de nuevas tecnologías?

Recuperado de https://www.semana.com/vida-moderna/articulo/aumento-de-suicidios-en-los-jovenes-por-lasnuevas-tecnologias $/ 549265$

Existen estudios (Durand Stern y Castillo, 2007) que señalan el posible efecto de la música en jóvenes que se suicidan, asimismo, no es ya un hecho nuevo la historia relacionada con ciertas bandas musicales y su aparente incitación a la autoviolencia o violentara otros, según los tipos de género, son los contenidos, por ejemplo la música banda popular mexicana, cuyos mensajes, se expresan sobre drogas, grupos de poder, cárteles, dinero, mujeres, fama, emerger de la pobreza a la riqueza, el regetón igualmente, en estos tres últimos aspectos. El investigador habilitado en esta inteligencia, deberá ser capaz de detectar géneros, contenidos, uso de los instrumentos, letras, su influencia en niños, adolescentes, adultos, situaciones, así como existe música romántica, lo hay para la destrucción.

Inteligencia lógico-matemática: Existen diversos tipos de peritos forenses, cuyo manejo de las matemáticas, física, es obligatorio, ya sea el perito químico o médico, para determinar cantidades de veneno, sustancias tóxicas, efectos en el cuerpo, tiempos de permanencia en este, modos de desecho corporal, igual en muertes por asfixia, ahogamiento, consumo de sustancias, entre tantos modos, donde se debe determinar cantidades, numeraciones, tiempos, describir mediante números los hechos y sus efectos.

Por otro lado, el perito balista, bombero, ingeniero, arquitecto, entre otros, cuya labor implique números, tiempos, cantidades; por ejemplo, alguna persona fallecida por exposición prolongada al calor (Narocki, 2016), o muerte por sumersión, cuánto tiempo 
implica o lleva a su deceso (Romero Polanco, 2007). En el caso del balista u otros, determinar trayectorias, puntos de salida, impacto en personas, casas, vehículos, entre otros (Calvo Zambrano y Duque Gutiérrez, 2016). Asimismo, para la perfilación criminal de la escena mediante los elementos anteriores.

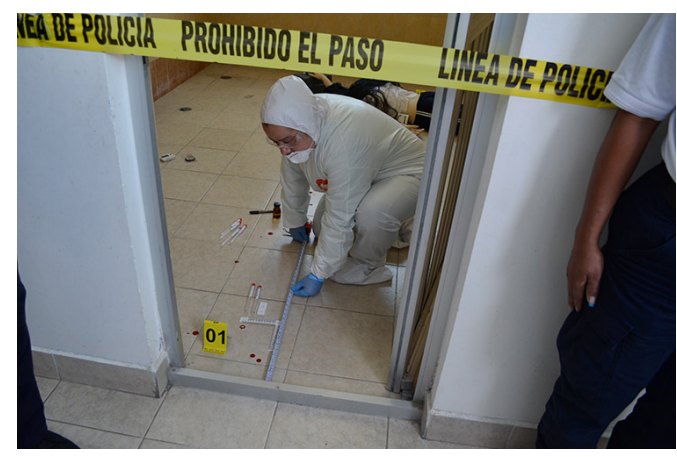

Figura 5. Criminalística de campo.

Recuperado de https://www.criminalistasforenses.org.mx/peritajes/criminalistica-de-campo

Inteligencia cenestésico-corporal: Nuevamente aplica para los profesionales de la psicología o criminología forense, para tener la habilidad de expresar empatía, saber comunicar tal mediante el cuerpo, las expresiones, mostrar el interés por las personas víctimas, no indiferencia, aburrimiento, sino generar ese rapport, si bien, pueden tener sobrecarga de casos, no hay que olvidar que al igual que nosotros, son seremos humanos, pero más vulnerados por la situación de crimen que han padecido. Si ocurriese desgaste laboral (Uribe Prado, López Flores, Pérez Galicia y García Saisó, 2014), este debe ser atendido para evitar ver a las personas como "uno más".

Y en esta ocasión para los abogados, jueces, tal vez al ser los primeros en recibir a una persona que ha padecido los efectos de un crimen, es muy escuchado de los casos de indiferencia por parte de los abogados receptores de las quejas, denuncias o demandas, lo que lleva a perder la confianza en las autoridades, no solo compete a abogados, sino a policías. 


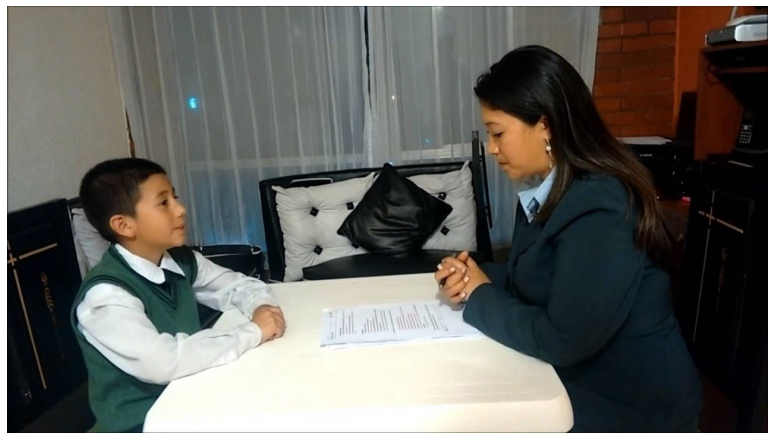

Figura 6. Entrevista psicología educativa. Recuperado de https://www.youtube.com/watch?v=2D0FpeToyGg

A continuación, "Atleta paralímpico no se rinde tras ser agredido en Metro de CDMX", resonado caso de burla a un invidente que al resultar lesionado en el sistema de transporte colectivo de metro, al querer denunciar, fue mofado por su condición de cegará al cuestionarle cómo iba a reconocer a su agresor si es ciego. Liga https://www.eluniversal. com.mx/metropoli/cdmx/atleta-paralimpico-no-se-rinde-tras-ser-agredido-en-metro-decdmx\#imagen-1

Inteligencia espacial: Esta inteligencia ligada a la naturalística y matemática, los peritos en criminalística de campo, física, balística, medicina, arqueólogo, entre otros, deben reconstruir mentalmente y digitalmente el espacio que envolvía un hecho presuntamente delictuoso, primero, claro es, mediante la imaginación, y con soporte en imágenes, vídeos, relatos, testigos, depende de su habilidad para percibir los hechos narrados o grabados con luz o video. No solo las escenas se pueden reconstruir, sino vehículos, accidentes principalmente (Agencia Iberoamericana para la Difusión de la Ciencia y la Tecnología, 2016), rostros de implicados con apoyo de los testigos presenciales, además de la reconstrucción de arqueólogos, antropólogos (Serrulla y Gómez, 2008) o artistas forenses, entre otros contextos. Véase la siguiente nota: "Realidad virtual para reconstruir crímenes, cada vez más cerca de los juzgados", https://www.bbc.com/mundo/video_ fotos/2015/01/150130_video_realidad_virtual_para_escenas_crimen_ig 


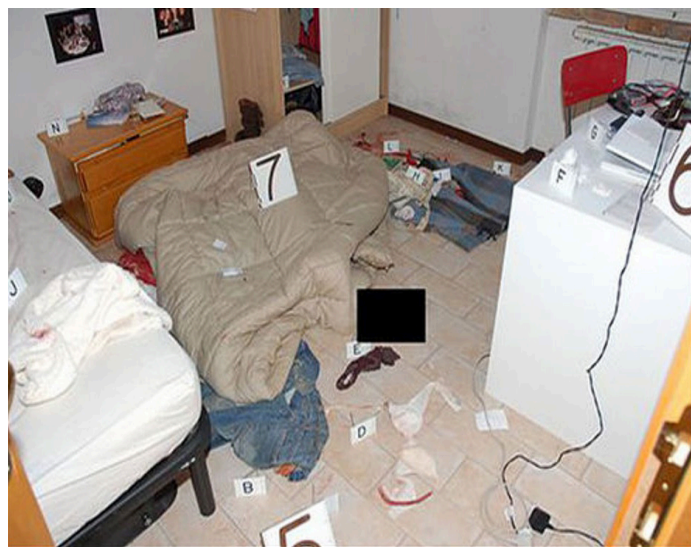

Figura 7. La escena del crimen tal y como la halló la policía.

Recuperado de http://www.teinteresa.es/sucesos/escena-crimen-hallo-policia_1_1075703303.html

Inteligencia intrapersonal: Se puede relacionar esta inteligencia con la ética profesional, no en el ejercicio profesional, sino desde los estudios preparatorios a antes de ingresar a un grado universitario, ya que jóvenes con poca claridad sobre las áreas forenses, criminales, periciales, carcelarias, militares, de seguridad, entre otras, ingresan a estas profesiones enfocados a gozar de los hechos más graves y complejos de la sociedad.

Basta mirar las páginas que se han levantado en homenaje a estas ciencias en redes digitales, Facebook, Twitter, Instagram, YouTube, entre tantas, donde abundan los vídeos e imágenes plagadas de sangre, gente que perdió la vida de modo siniestral, autopsias, vehículos policiales, del servicio forense, jóvenes que presumen fotos en cementerios, en el servicio médico forense, en sus prácticas profesionales, portando armas, cartuchos, o expresando su frialdad ante hechos criminales y sobre las víctimas. Los medios digitales son un continuación de los medios de comunicación; es decir, son medios a través de los cuales, la gente se conecta con el mundo para informarse, no para desorientarse (Fernández, 2011). 


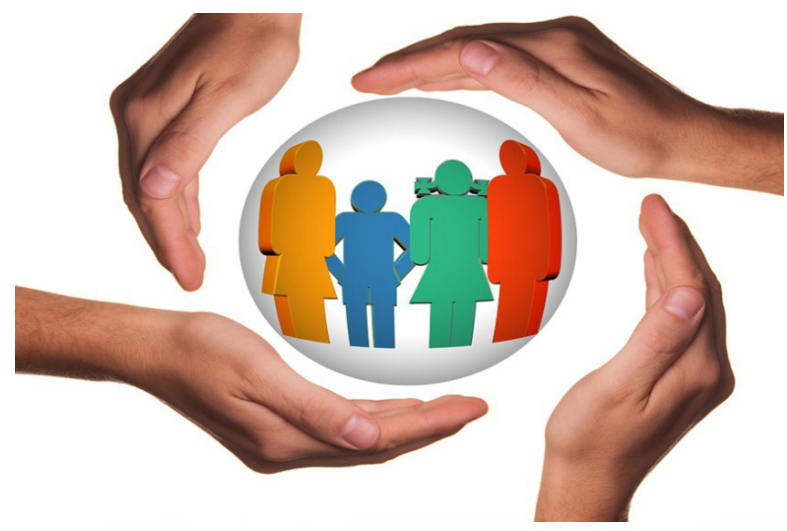

Figura 8. Protocolo para atender y proteger a las víctimas de violencia.Recuperado de https://observatorioviolencia.pe/protocolo-para-atender-y-proteger-a-las-victimas-de-violencia

Inteligencia interpersonal: Tal cual se toma con la descripción de este tipo de inteligencia, el psicólogo, psiquiatra, victimólogo, criminólogo, deben interesarse por los intereses de los demás, conocer sus motivaciones, tanto para haber cometido un delito, así como su interpretación al padecerlo, recordar el caso, los detalles, buscar modos de apoyar a las personas, comprenderles.

Tratando de ello, se presentan dos casos, uno altamente resonante, del llamado "Monstruo de Ecatepec", que de primera mano, se puede resaltar un odio grande a las mujeres que se derivaba desde el trato que le daba su madre, una venganza arrastrada y desplazada a otras mujeres a un modo extremo de engañarlas a través de su esposa para llevarlas a su casa, ahí asesinarlas, para luego descuartizarlas y cocinarlas en comida. Estos fueron descubiertos mientras caminaban con una carriola para bebé, que no portaban a tal, sino a huesos humanos.

Liga a "Las maté por bonitas' dijo el 'Monstruo de Ecatepec"”, https://www.excelsior.com. $\mathrm{mx} /$ comunidad/las-mate-por-bonitas-dijo-el-monstruo-de-ecatepec/1270387, por otro lado, el relato de una víctima: D"esgarrador relato de menor violada por diez hombres", https:// www.elpatagonico.com/desgarrador-relato-menor-violada-diez-hombres-n5025843

Inteligencia naturalística: Finalmente, este tipo de inteligencia para los profesionales mencionados, ocupa el conocer el contexto, cómo este es percibido para conocer la cultura de las personas que le habitan. Cada país tiene culturas y leyes propias, que pueden ser muy diferentes entre sí. Incluso hay conductas que en un sitio son delito y en otro no, por ejemplo, 
el aborto en México sigue siendo criminalizado en algunas regiones, en el artículo "Abortar en México: ¿en qué estados se criminaliza más a las mujeres por interrumpir el embarazo?” https://www.animalpolitico.com/2018/08/abortar-mexico-mujeres-estados/, donde explica en que regiones no es delito y en cuáles si, lo mismo entre países.

Por otro lado, más de la mitad del mundo, no tiene igualdad sobre la unión entre personas del mismo sexo, incluso, hay sitios donde se aplica la muerte o cárcel, véase la siguiente nota titulada "Lapidación de gays en Brunéi: el mapa que muestra los países que castigan con pena de muerte las relaciones homosexuales" en https://www.bbc.com/mundo/ noticias-47806575. Qué decir del consumo de drogas, tema por demás controversial entre quienes apoyan el consumo medicinal, recreativo, o quiénes están en contra por el crimen organizado, muy complejo tópico.

Esta inteligencia, por un lado, nos puede ayudar a comprender la cultura, tradiciones, ambientes naturales que hay, y que determinan la conducta de los sujetos. Por otro lado, para los peritos en biología, química, antropología, medicina, u otros, el ambiente genera condiciones sobre los cuerpos, ya sea por calor, frío, humedad, resequedad, putrefacción (Hernández Espinoza, 2016; De Luca, 2011).

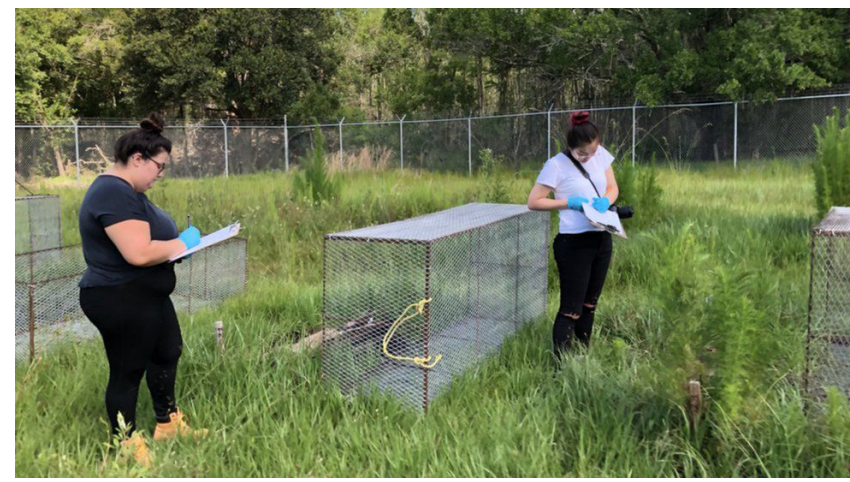

Figura 8. Qué son las "granjas de cadáveres" donde los cuerpos humanos se descomponen a la intemperie (y por qué causan controversia incluso entre científicos).

Recuperado de https://www.bbc.com/mundo/noticias-48538093

Hay hechos donde intervienen animales; por ejemplo, la siguiente nota "Sicarios hacen que perro devore genitales de supuesto violador", https://www.contramuro.com/sicarioshacen-que-perro-devore-genitales-de-supuesto-violador/, o "Canibalismo narco: sicarios mexicanos preparan platillos autóctonos con la carne de sus víctimas", https://www. 
infobae.com/america/mexico/2017/07/19/canibalismo-narco-sicarios-mexicanos-preparanplatillos-autoctonos-con-la-carne-de-sus-victimas/, donde ha de intervenir el especialista en veterinaria forense (Friedrich, 2015). En otro tema, el investigador debe ser muy perceptivo para ir en búsqueda del vestigio, de aquello que le indique dónde hay más sobre el hecho, debe ser curioso, por lo cual, es necesario explorar con los sentidos el lugar que le rodea.

\section{RESPONSABILIDAD PROFESIONAL Y ÉTICA}

En todo caso, la formación para el desarrollo de las inteligencias, depende mucho de los estudios universitarios, de la voluntad del mismo profesional en formación, así como las habilidades que durante el desempeño laboral, adquiera. Al respecto señala Escobar Maralunda cómo podría ser la formación para cualquiera que se dedique a las áreas criminales, forenses, penitenciarias, de atención a víctimas, etcétera:

En este sentido, creo que la formación (...) debe orientarse a la formación de personas. Personas que, de una u otra forma, estarán destinadas a trabajar con los problemas más serios y complejos de la sociedad y que, por ende, requieren de una amplia y sólida formación. No basta la mera capacitación para un oficio determinado, ni que el instrumento del que están a cargo funcione de una determinada forma. Es preciso que ese ejercicio o actividad se ejerza desde la conciencia y el conocimiento de las implicaciones sociales que el mismo tiene

(2008, p. 2).

En ese sentido expresado, el profesional de cualquiera de estas áreas debe comenzar por la empatía sobre los hechos que ha de atender, que podría concentrarse en la inteligencia intrapersonal e interpersonal.

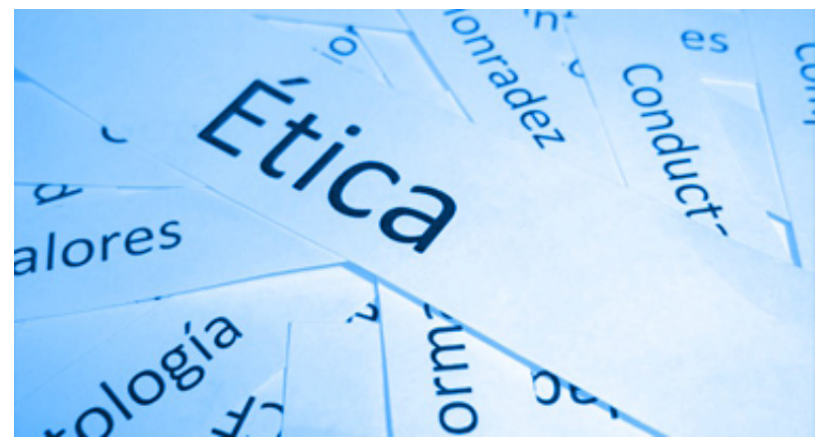

Figura 10. Lecciones sobre deontología del periodista en la era digital. Recuperado de https://www.clasesdeperiodismo.com/2016/04/12/lecciones-sobre-deontologia-del-periodista-en-la-era-digital 
Deben existir exámenes rigurosos sobre los aspirantes a estudiar psicología criminal, psicología forense, psiquiatría forense, medicina forense, criminalística, criminología, derecho penal, victimología forense, u otras, exámenes psicológicos, físicos, prospectivos, de valores, moral, respeto, ya que de ellos dependerán áreas tan importantes como lo son la administración de justicia, el trato con víctimas, el tratamiento penitenciario, y en general el trato con las personas. Por otro lado, ser capaz de autoreconocerse apto o no para atender estas situaciones con respeto, prudencia, altruismo, empatía, deben saber si serán capaces de ser agentes de cambio, transformadores, con compromiso social y responsabilidad, regenerar el tejido social y personal (Sáenz Obregón, 2011).

\section{CONCLUSIONES}

Los profesionales relacionados con las áreas de administración de justicia, ámbito penitenciario, victimal, derechos humanos $\mathrm{u}$ otros, deben ser meticuloso en el tratamiento de los casos que aborda, siendo de apto de conocer sus capacidades y áreas de oportunidad, para con ello, desarrollar los diferentes tipos de inteligencias, ya sea, para intervenir mejor en los casos o descartarse de determinados, teniendo la conciencia de que sus funciones y resultados están en razón del mejoramiento de la sociedad, y para la administración de justicia. Los ejemplos mostrados aquí, son limitados, pero el lector podrá identificar las inteligencias mostradas en otros casos, donde sean necesarias aplicarlas y ampliarlas. En la siguiente tabla se muestra un resumen de los tipos de inteligencia y las habilidades a desarrollar. 
Tipo de inteligencia

Inteligencia

lingüística

teligencia

musical

Inteligencia

lógico-matemática

Inteligencia

cenestésico-corporal

Inteligencia espacial

Inteligencia intrapersonal

Inteligencia interpersonal

Inteligencia naturalística

\section{Habilidad}

Tipo de casos

Expresión oral, rapport, empatía, comunicación Entrevista psicológica, exitosa, obtención de información veraz, negociación, fomentar la apertura, receptividad, paforense, a víctimas, testigos, delincuentes. ciencia, establecimiento de conexiones.

Percepción, detección de influencias externas, Suicidios, influencias negatiidentificación, interpretación.

vas, imitación criminal

Percepción, reconstrucción, medición, cuantificaciones, interpretación de fenómenos alrededor de los sujetos, observación.

Perfilación criminal de la escena, reconstrucción, mediciones de posiciones, interpretación de estas.

Expresión oral, rapport, empatía, comunicación exitosa, obtención de información veraz, negociación, fomentar la apertura, receptividad, paciencia, establecimiento de conexiones.

Percepción, reconstrucción, medición, cuantificaciones, interpretación de fenómenos alrededor de los sujetos, observación.

Entrevista psicológica, forense, a víctimas, testigos, delincuentes.

Perfilación criminal de la escena, reconstrucción, mediciones de posiciones, interpretación de estas.

Ética, responsabilidad, autoconocimiento, autoestima, respeto, prudencia, discreción.

Aptitud para atender un caso particular con ética.

Empatía, ética, respeto, discreción.

Atención a víctimas o personas detenidas, familiares.

Interés por el otro, comprensión, empatía, posicionarse en su lugar. Percepción, identificación, reconstrucción.

Tabla 1. Elaboración propia.
Perfilación criminal de la escena, reconstrucción, mediciones de posiciones, interpretación de estas. 


\section{REFERENCIAS}

I Agencia Iberoamericana para la Difusión de la Ciencia y la Tecnología (2015). Un sistema reconstruye los accidentes de tráfico en 3D para estimar cómo se produjeron. Recuperado de http://www.dicyt.com/ quienes-somos

I Alvarez, B. (5 de septiembre 2019). Sicarios hacen que perro devore genitales de supuesto violador. Contramuro. Recuperado de https://www.contramuro.com/sicarios-hacen-que-perro-devore-genitales-desupuesto-violador/

I Alzaga, I. (13 de agosto de 2019). PGJ busca a taxista que presuntamente viola a pasajeras cerca de AICM. Milenio. Recuperado de https://www.milenio.com/policia/aicm-opera-taxista-presuntamenteviola-pasajeras

I Appleford, S. (12 de febrero 2019). Satanismo, quema de iglesias y asesinatos: la verdadera historia de 'Lords of Chaos'. Los Angeles Times. Recuperado de https://www.latimes.com/espanol/entretenimiento/ la-en-satanismo-quema-de-iglesias-y-asesinatos-la-verdadera-historia-de-lords-of-chaos-20190212-story. html

I BBC News (3 de abril de 2019). Lapidación de gays en Brunéi: el mapa que muestra los países que castigan con pena de muerte las relaciones homosexuales. BBC. Recuperado de https://www.bbc.com/ mundo/noticias-47806575

I Calvo Zambrano, N. y Duque Gutiérrez, V. (2016). Determinación del ángulo de impacto y de disparo basado en la forma del orificio de entrada del proyectil en superficies de vehículos (tesis de maestría). Universidad Tecnológica de Pereira, Pereira, Risaralda, Colombia. Recuperado de http://repositorio.utp. edu.co/dspace/bitstream/handle/11059/6932/530144C169.pdf?sequence=1\&isAllowed=y

I De Luca, S.(2011). Identificación humana en antropología forense: aportaciones para la estimación de sexoy edad(tesisdoctoral).UniversidaddeGranada,Granada,España.Recuperadodehttp://digibug.ugr.es/bitstream/ handle/10481/21023/2072570x.pdf;jsessionid=D0278B862AF49CD35339CE618D036D47? sequence=1

1 Desgarrador relato de menor violada por diez hombres (11 de abril 2019). El Patagónico. Recuperado de https://www.elpatagonico.com/desgarrador-relato-menor-violada-diez-hombres-n5025843

I Dorta-Armaignac, K. (2010). Los estudios sobre productos culturales en el Caribe contemporáneo: Primeras reflexiones. Ciencia en su PC. 4, 18-32. Recuperado de http://www.redalyc.org/pdf/1813/181317854002. pdf 
I Durand Stern, L. y Castillo, Del, M.T. (2007). Influencia de la música en jóvenes con tendencias suicidas. Revista Electrónica de Psicología Iztacala. 10(2), 11-30. Recuperado de http://www.iztacala.unam.mx/ carreras/psicologia/psiclin/vol10num2/art2V10N2jun07.pdf

I En Estados Unidos una operadora del 911 cortó miles de llamadas de emergencia. (13 de octubre 2016). El Universal. Recuperado de https://www.eluniverso.com/noticias/2016/10/13/nota/5852056/estadosunidos-operadora-911-corto-miles-llamadas-emergencia

$\checkmark$ Escobar Marulanda, G. (2006). La enseñanza en criminología. Algunas consideraciones. Revista Electrónica de Ciencia Penal y Criminología. 8, 1-8. Recuperado de http://criminet.ugr.es/recpc/08/ recpc08-r2.pdf

I Fernández, A. (2011). Herbert Marcuse: La racionalidad tecnológica unidimensional como aporte a la teoría crítica. Revista POSTData: Revista de Reflexión y Análisis Político. 1(61), 111-123. Recuperado de https://drive.google.com/file/d/0B637k_n5waBpb1VJMUhRMmpaTVU/view

I Fregoso, J. (19 de julio 2017). Canibalismo narco: sicarios mexicanos preparan platillos autóctonos con la carne de sus víctimas. Infobase. Recuperado de https://www.infobae.com/america/mexico/2017/07/19/ canibalismo-narco-sicarios-mexicanos-preparan-platillos-autoctonos-con-la-carne-de-sus-victimas/

I Friedrich, N. (2015), Medicina veterinaria legal y forense. Desarrollo y futuro. Casos periciales. Medicina Legal de Costa Rica. 32(1). Recuperado de https://www.scielo.sa.cr/pdf/mlcr/v32n1/art24v32n1.pdf

I Hernández Espinoza, P.O. (2016). El proceso de identificación en el caso de material óseo histórico: reflexiones para la antropología forense. Anales de Antropología. 50, 266-287. Recuperado de https://cutt. ly/dyAmx $5 \mathrm{a}$

I Macías, M.A. (2002). Las múltiples inteligencias. Psicología desde el Caribe. 10. 27-38. Recuperado de http://rcientificas.uninorte.edu.co/index.php/psicologia/article/viewFile/1671/9417

I Mata, S., Gómez-Pérez, M.M. y Calero, M.D. (2017). Resolución de problemas interpersonales en niños en exclusión social: Valoración de un programa de entrenamiento. Revista Latinoamericana de Psicología. 50(2), 107-116. Recuperado de https://blogs.konradlorenz.edu.co/files/16186.pdf

I Narocki, C. (2016). Informe: Siniestralidad Relacionada con la Exposición a Altas Temperaturas Durante el Año 2015. Valencia: Instituto Sindical de Trabajo, Ambiente y Salud. Recuperado de http://www.istas. ccoo.es/descargas/Informe\%20siniestralidad\%20laboral\%20altas\%20temperaturas.pdf

I Novo, M., Herbón, J. y Amado, B.G. (2016). Género y victimización: efectos en la evaluación de la violencia psicológicas util y manifiesta, apego adulto y tácticas de resolución de conflictos. Revista Iberomaricana 
de Psicología y Salud. 7, 89-97. Recuperado de https://cutt.ly/wyAmngJLuca, De, S.L. (2004). El docente y las inteligencias múltiples. Revista Iberoamericana de Educación. 34(1), 1-11. Recuperado de https:// rieoei.org/historico/deloslectores/616Luca.PDF

I Realidad virtual para reconstruir crímenes, cada vez más cerca de los juzgados. (31 de enero 2013). $B B C$. Recuperado de https://www.bbc.com/mundo/video_fotos/2015/01/150130_video_realidad_virtual_para_ escenas_crimen_ig

I Redacción Animal Político (12 de diciembre 2018). Abortar en México: ¿en qué estados se criminaliza más a las mujeres por interrumpir el embarazo? Animal Político. Recuperado de https://www.animalpolitico. com/2018/08/abortar-mexico-mujeres-estados/

I Reséndiz, Y. (09 de octubre 2018). “'Las maté por bonitas' dijo el 'Monstruo de Ecatepec"'. Excelsior. Recuperado de https://www.excelsior.com.mx/comunidad/las-mate-por-bonitas-dijo-el-monstruo-deecatepec/1270387

I Romero Polanco, J.L. (2007). Muertes por sumersión. Revisión y actualización de un tema clásico de la medicina forense. Cuadernos de Medicina Forense. 13(48-49), 99-130. Recuperado de http://scielo.isciii. es/pdf/cmf/n48-49/art01.pdf

I Sáenz Obregón, J. (2011). La pedagogía ciudadana en Bogotá: ¿un proyecto autoritario o el mínimo común necesario para la construcción de una democracia radical? Revista Educación y Pedagogía. 23(60), 137145. Recuperado de https://dialnet.unirioja.es/descarga/articulo/4157829.pdf

I Serrulla, F. y Gómez, M. (2008). Aplicaciones de la técnica de aproximación facial forense en la identificación humana individual. Cuadernos de Medicina Forense. 14(53-54), 291-307. Recuperado de http://scielo.isciii.es/pdf/cmf/n53-54/10.pdf

I Suárez, J., Maíz, F. y Meza, M. (2010). Inteligencias múltiples: una innovación pedagógica para potenciar el proceso enseñanza aprendizaje. Investigación y Postgrado. 25(1), 81-94. Recuperado de https://www. redalyc.org/pdf/658/65822264005.pdf

I Tequianes, E. (18 de mayo 2018). Atleta paralímpico no se rinde tras ser agredido en Metro de CDMX. El Universal. Recuperado de https://www.eluniversal.com.mx/metropoli/cdmx/atleta-paralimpico-no-serinde-tras-ser-agredido-en-metro-de-cdmx\#imagen-1

1 Uribe Prado, J.F., López Flores, P.R., Pérez Galicia, C. y García Saisó, A. (2014). Síndrome de Desgaste Ocupacional (Burnout) y su Relación con Salud y Riesgo Psicosocial en Funcionarios Públicos que Imparten Justicia en México, D.F. Acta de Investigación Psicológica. 4(2), 1554-1571. Recuperado de http://www.scielo.org.mx/pdf/aip/v4n2/v4n2a8.pdf 
I Velásquez de Romero, Y. (2016). Teoría de las múltiples inteligencias y su aplicabilidad en la enseñanza de la lengua extranjera: Inglés. Revista de Ciencias de la Educación. 26(47), 148-170. Recuperado de http:// servicio.bc.uc.edu.ve/educacion/revista/47/art09.pdf

Envío a dictamen: 11 de febrero de 2020

Reevío: 28 de abril de 2020

Aprobación: 29 de abril de 2020

Wael Sarwat Hikal Carreón. Doctorando en Filosofía con Acentuación en Estudios de la Educación (becario Consejo Nacional de Ciencia y Tecnología) por la Facultad de Filosofía y Letras de la Universidad Autónoma de Nuevo León. Correo electrónico: wael.hikalcrr@, uanl.edu.mx. 